\title{
Erratum to: Phagocytic Activity of Rat Primary Astrocytes Is Regulated by Insulin and Ganglioside GM1
}

\author{
T. V. Sokolova ${ }^{a}{ }^{* *}$, M. P. Rychkova ${ }^{a}$, N. E. Basova ${ }^{a}$, D. S. Vasilev ${ }^{a}$, \\ N. F. Avrova ${ }^{a}$, and M. G. Yefimova ${ }^{a, * *}$ \\ ${ }^{a}$ Sechenov Institute of Evolutionary Physiology and Biochemistry, Russian Academy of Sciences, \\ St. Petersburg, Russia \\ *e-mail: sokolt1956@mail.ru \\ **e-mail:yefimova3@gmail.com
}

Received November 29, 2021

Revised November 29, 2021

Accepted November 29, 2021

DOI: $10.1134 / \mathrm{S} 0022093021060302$

The article "Phagocytic Activity of Rat Primary Astrocytes Is Regulated by Insulin and Ganglioside GM1", written by T. V. Sokolova, M. P. Rychkova, N. E. Basova, D. S. Vasilev, N. F. Avrova, and M. G. Yefimova, was originally published electronically in Springer-Link on 26 October 2021 without Open Access. After publication in volume 57, issue 5, pages 1072-1080 the authors decided to make the article an Open Access publication. Therefore, the copyright of the article has been changed to (C) The Author(s) 2021 and the article is forthwith distributed under the terms of a Creative Commons Attribution 4.0 International License (http://creativecommons.org/licenses/ by/4.0/, CC BY), which permits use, duplication, adaptation, distribution and reproduction of a work in any medium or format, as long as you cite the original author(s) and publication source, provide a link to the Creative Commons license, and indicate if changes were made.

The original article can be found online at https://doi.org/10.1134/S0022093021050094 